\title{
Symptomatic and essential palatal tremor. 3. Abnormal motor learning
}

\author{
G Deuschl, C Toro, J Valls-Solé, M Hallett
}

\begin{abstract}
Background-Palatal tremor is divided into symptomatic palatal tremor (SPT) and essential palatal tremor (EPT) on the basis of clinical features. The inferior olive seems to be abnormal in SPT, but not EPT. Because the inferior olive is likely to be involved in several types of motor learning, it is hypothesised that motor learning would be abnormal in patients with SPT, but not those with EPT.

Methods-In six patients with SPT and four patients with EPT, two motor learning paradigms were studied-the classical conditioning of an acoustically elicited eyeblink with electrical supraorbital nerve shock and a test of adaptation of ballistic arm movements to a change of the gain.
\end{abstract}

Results-Classical conditioning was impaired unilaterally or bilaterally in the patients with SPT, depending on whether they had unilateral or bilateral abnormalities of the inferior olives, except for the two least affected patients. All but one of the patients with EPT had normal conditioning. On the adaptation test of arm movements, most of the patients with SPT had impaired learning of the arm contralateral to the hypertrophied inferior olive, regardless of whether the abnormality was unilateral or bilateral, but all patients with EPT had normal results.

Conclusions-In SPT pseudohypertrophy of the inferior olive leads to defective cerebellar function, whereas in EPT the inferior olive functions normally.

\section{$(千$ Neurol Neurosurg Psychiatry 1996;60:520-525)}

Human Motor Control Section, Medical Neurology Branch, National Institute of Neurological Disorders and Stroke, National Institutes of Health, Bethesda, MD, USA G Deusch C Toro

J Valls-Solé

$M$ Hallett

Correspondence to: Dr Mark Hallett, Building 10, Room 5N226, 10 Cente Dr MSC 1428 , Bethesda, MD 20892-1428, USA.

Received 10 March 1995 and in revised form Accepted 30 November 1995

Keywords: palatal tremor; inferior olive; motor learning; cerebellar disease

Palatal tremor is a rhythmic movement disorder characterised by continuous movements of the soft palate and sometimes involving additional muscles. This condition is often accompanied by an abnormality of the inferior olive characterised by hypertrophy ${ }^{1-3}$ with swollen cells and an increase of glial tissue. ${ }^{4-6}$ This so called olivary pseudohypertrophy is thought to develop after a lesion in the pathway from the contralateral dentate nucleus to the inferior olive via the red nucleus and the central tegmental tract. If pseudohypertrophy of the inferior olive underlies the pathophysiology of palatal tremor, it may be expected that other functional disturbances of the inferior olive can be identified.

In earlier studies, ${ }^{67}$ we have shown that patients with palatal tremor can be separated into two groups: symptomatic palatal tremor (SPT) and essential palatal tremor (EPT). Among several features separating these conditions are areas of hyperintensity on MRI at the level of the inferior olive in the patients with SPT, but not in the patients with EPT. The abnormal signals very likely represent olivary pseudohypertrophy, which we think is restricted to SPT and does not occur in EPT. Along with these morphological abnormalities in SPT, there is clinical evidence of cerebellar deficits of varying severity. ${ }^{7} \mathrm{We}$ attempted to investigate quantitatively the olivary functions with motor learning tests, because there is evidence that the cerebellum and its associated circuitry are necessary for motor learning to take place..$^{8-13} \mathrm{We}$ selected classical conditioning, one of the most extensively studied learning paradigms, ${ }^{1011}$ and adaptation of arm movements, because both tests reveal clearcut abnormalities in patients with cerebellar deficits. ${ }^{13} 14$

\section{Methods}

We studied 10 patients with palatal tremor (six with SPT and four with EPT). The table summarises their clinical characteristics. These are reported in detail elsewhere. ${ }^{7}$ The patients' hearing was normal. Twenty six age matched normal volunteers, 16 for the classical conditioning paradigm and 10 for the adaptation paradigm, served as control subjects. The protocol was approved by the Institutional Review Board, and all subjects gave their written informed consent for the study.

\section{EXPERIMENTAL METHODS}

Other papers describe the methodologies for eyeblink conditioning ${ }^{12}$ and adaptation motor learning ${ }^{13}$ and, therefore, the tests are only briefly summarised here. For eyeblink conditioning, pairs of surface cutaneous electrodes were placed over the upper and lower orbicularis oculi muscles on both sides of the face. The conditioned stimulus was an auditory tone of $90 \mathrm{~dB}$ applied for $400 \mathrm{~ms}$ through earphones to both ears simultaneously. The unconditioned stimulus was an electrical shock of $0.5 \mathrm{~ms}$ duration applied to the right supraorbital nerve at an intensity of three to five times the sensory threshold. In some 
Table 1 Clinical characteristics of patients with palatal tremor

\begin{tabular}{|c|c|c|c|c|c|}
\hline Patient & $\begin{array}{l}\text { Sexlage } \\
(y)\end{array}$ & $\begin{array}{l}\text { Palatal } \\
\text { tremor } \\
\text { duration } \\
\text { (y) }\end{array}$ & $\begin{array}{l}\text { Palatal tremor } \\
\text { and other symptoms }\end{array}$ & Other diseases & $\begin{array}{l}\text { Pendular } \\
\text { nystagmus }\end{array}$ \\
\hline \multicolumn{6}{|l|}{ Essential palatal tremor: } \\
\hline 1 & $F / 48$ & 25 & $\begin{array}{l}\text { Ear clicks, left > right; } \\
\text { increased with stress }\end{array}$ & $\begin{array}{l}\text { Temporomandibular } \\
\text { joint disease }\end{array}$ & None \\
\hline 2 & $\mathrm{~F} / 60$ & 15 & $\begin{array}{l}\text { Ear clicks, left > right; } \\
\text { increased with stress, } \\
\text { stopped with speaking } \\
\text { and singing }\end{array}$ & $\begin{array}{l}\text { Temporomandibular } \\
\text { joint disease }\end{array}$ & None \\
\hline 3 & $\mathrm{M} / 61$ & 3 & $\begin{array}{l}\text { Ear clicks, left; increased } \\
\text { with stress }\end{array}$ & None & None \\
\hline 4 & $M / 42$ & 14 & $\begin{array}{l}\text { Ear clicks, left; increased } \\
\text { with stress and sleep } \\
\text { deprivation }\end{array}$ & $\begin{array}{l}\text { Postural and } \\
\text { action tremor }\end{array}$ & None \\
\hline \multicolumn{6}{|l|}{ Symptomatic palatal } \\
\hline 5 & $\mathrm{M} / 76$ & $>3$ & $\begin{array}{l}\text { Degenerative ataxia; gait } \\
\text { and extremity ataxia; } \\
\text { dysarthria }\end{array}$ & None & $\begin{array}{l}\text { Vertical, bilateral, } \\
\text { symmetric }\end{array}$ \\
\hline 6 & $F / 58$ & 2 & $\begin{array}{l}\text { Brain stem abscess; } \\
\text { oscillopsia; gait and right } \\
\text { sided extremity ataxia }\end{array}$ & None & $\begin{array}{l}\text { Vertical, torsional, } \\
\text { right }>\text { left }\end{array}$ \\
\hline 7 & $\mathrm{M} / 52$ & 12 & $\begin{array}{l}\text { Brain stem haemorrhage } \\
\text { (cavernoma); oscillopsia, } \\
\text { left > right; gait and right } \\
\text { sided extremity ataxia }\end{array}$ & $\begin{array}{l}\text { Surgical removal of } \\
\text { thyroid gland }\end{array}$ & $\begin{array}{l}\text { Vertical, torsional, } \\
\text { right }\end{array}$ \\
\hline 8 & $\mathrm{~F} / 66$ & 2 & $\begin{array}{l}\text { Stroke; oscillopsia; gait } \\
\text { and extremity ataxia; } \\
\text { dysarthria }\end{array}$ & $\begin{array}{l}\text { Diabetes, arteriosclerotic } \\
\text { vascular disease, gall } \\
\text { bladder disease }\end{array}$ & $\begin{array}{l}\text { Vertical, bilateral, } \\
\text { symmetric }\end{array}$ \\
\hline 9 & $\mathrm{M} / 61$ & 5 & $\begin{array}{l}\text { Stroke; oscillopsia; gait } \\
\text { and extremity ataxia; } \\
\text { dysarthria }\end{array}$ & None & $\begin{array}{l}\text { Vertical, bilateral, } \\
\text { symmetric }\end{array}$ \\
\hline 10 & $\mathrm{M} / 38$ & 7 & $\begin{array}{l}\text { Brain stem haemorrhage } \\
\text { (cavernoma); oscillopsia; } \\
\text { gait and right sided } \\
\text { extremity ataxia }\end{array}$ & None & $\begin{array}{l}\text { Vertical, torsional, } \\
\text { right }>\text { left }\end{array}$ \\
\hline
\end{tabular}

Modified from Deuschl et al. ${ }^{7}$

patients, the conditioning with electrical stimuli to the left supraorbital nerve was tested separately in a second experiment. The subjects were seated comfortably and kept their eyes open during the test. The conditioned (auditory) stimulus and the unconditioned (electrical) stimulus were coupled, with the electrical shock being delivered just at the end of the tone. Coupled stimuli were given for eight consecutive trials, followed by two test trials: one with the auditory stimulus alone and one with the electrical stimulus alone. Ten to 15 seconds were allowed between each trial. Each block of 10 trials was repeated eight times.

The EMG signals were rectified and smoothed with a time constant of $10 \mathrm{~ms}$. A conditioned response was defined as EMG activity with an amplitude of more than $2 \mu \mathrm{V}$ in the orbicularis oculi muscles on both sides of the face and preceding the unconditioned stimulus by less than 200 ms. Without conditioning, the baseline activity was always below $1 \mu \mathrm{V}$. The same definition applied to the trials with the conditioned stimulus alone.

For adaptation motor learning, the motor learning task was to match a ballistic movement of the forearm to a target alternating between two positions on a computer screen. The subject had to make the cursor follow the target movements with a single, rapid elbow flexion or extension, with emphasis on speed rather than accuracy. The gain between arm and cursor movements was adjusted so that an elbow rotation of $13.5^{\circ}$ resulted in a $13.5 \mathrm{~cm}$ cursor displacement (gain $=1.0 \mathrm{~cm} /{ }^{\circ}$ ). After a few practice trials, the subject performed 40 movements between the right and left targets (baseline trials). Between trials 40 and 41, the gain of the system was suddenly increased so that an elbow rotation of $9.5^{\circ}$ produced a cursor displacement of $13.5 \mathrm{~cm} \mathrm{(gain}=1.42$ $\mathrm{cm} /{ }^{\circ}$ ), and the subject performed another 40 movements between the targets (test trials).

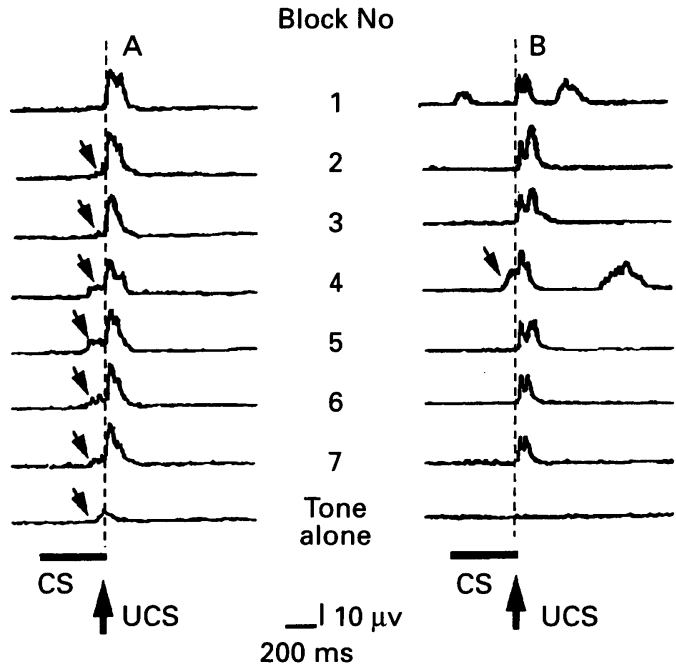

Figure 1 Conditioned EMG responses from the lower eyelid in a patient with EPT $(A)$ and a patient with SPT (B). Traces are examples from seven consecutive blocks of trials with paired conditioned and unconditioned stimuli. The eighth trace is with the acoustic stimulus alone in the seventh block. The bars indicate the conditioned stimulus (CS). The large arrows indicate delivery of the unconditioned stimulus (UCS). The small arrows indicate the appearance of the conditioned responses. Conditioned responses are frequent in the patient with EPT, but almost absent in the patient with SPT. 
Figure 2 Number of conditioned responses (mean $(S D)$ ) as a function of the block number in the normal subjects. After five blocks, there is no additional increase in the number of conditioned responses.

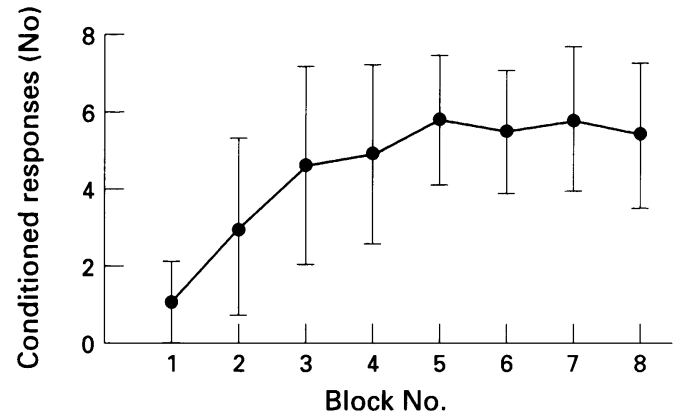

DATA ANALYSIS

The methods used for analysis of the data from the adaptation motor learning task are described elsewhere. ${ }^{13}$ Briefly, the absolute movement amplitude and movement duration were measured and an exponential function was fitted to the amplitude values obtained after the change of the gain, according to a least square algorithm. The exponent $\tau$ of this exponential function is considered to measure the speed of learning.
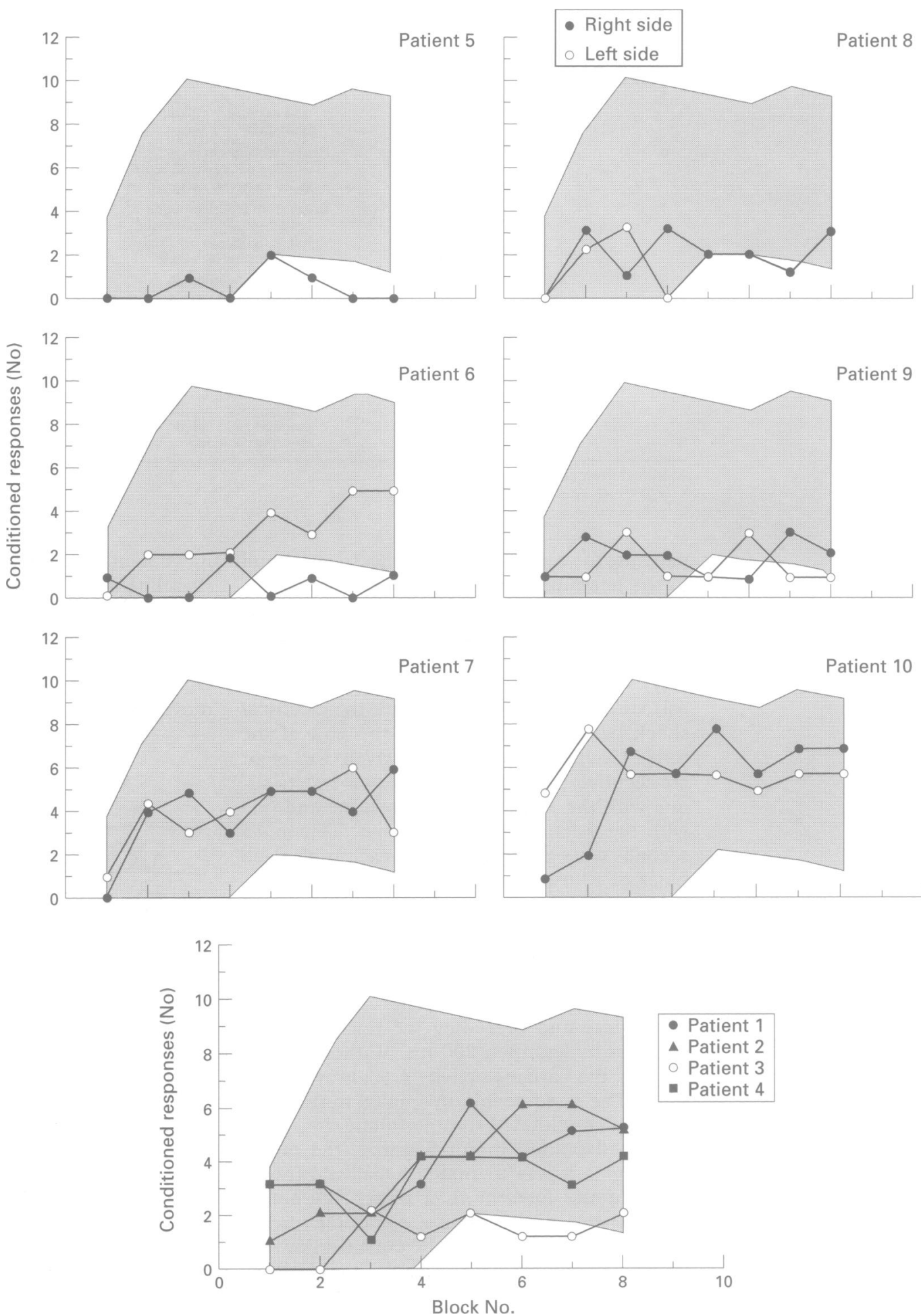

Figure 3 Individual results of the conditioning test in six patients with SPT (top) and four patients with EPT (bottom). The shaded areas indicate the (two sided) $98 \%$ confidence intervals of the normal subjects. Whenever clinical or MRI asymmetries were present, the patients were tested with both right sided and left sided unconditioned stimuli. Abnormal conditioning is evident in four patients with $S P T(5,6,8$, and 9) and one patient with EPT (3). One patient with SPT (6) shows only unilateral abnormal conditioning. 
Figure 4 Mean movement amplitudes in normal subjects and patients with EPT $(A)$ and in normal subjects and patients with SPT (except patient 8) (B) for all the trials. The horizontal lines indicate the target amplitudes for the $13.5^{\circ}$ position $(*)$ and the $9 \cdot 5^{\circ}$ position $\left({ }^{\star \star}\right)$. The arrows indicate the change of the gain. After the gain was changed, the movement amplitude decreased, with a more rapid drop in the normal subjects and patients with EPT than in the patients with SPT.
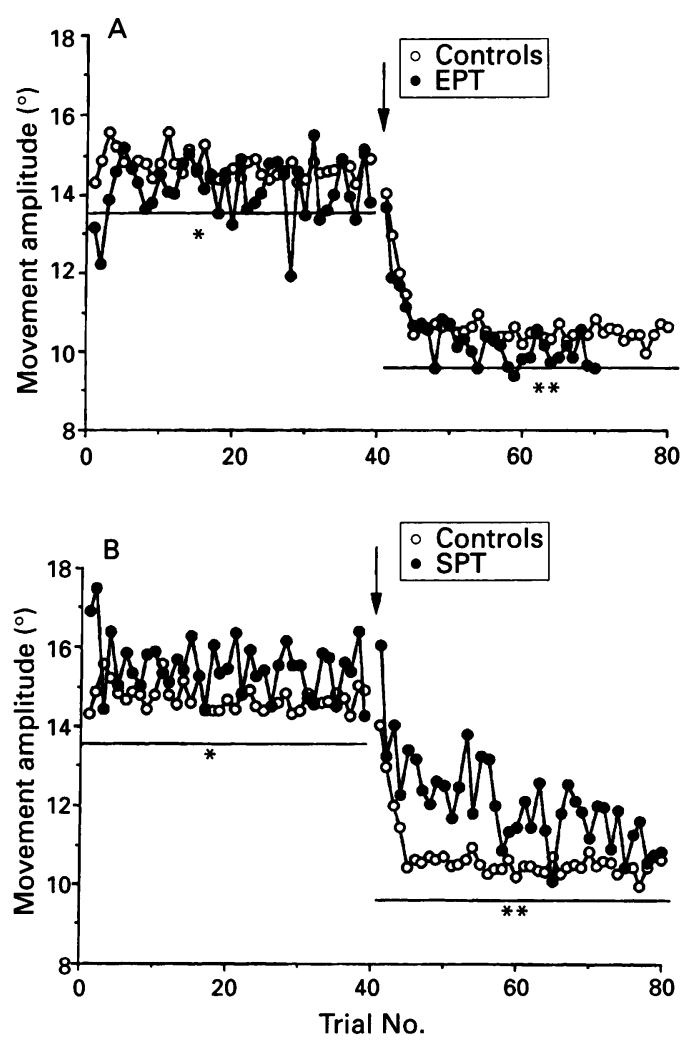

Results

CLINICAL AND MRI FINDINGS

Three patients with SPT had bilateral palatal tremor and bilateral cerebellar symptoms, and the other three had unilateral palatal tremor on the right side and a right sided cerebellar syndrome. Brain MRI of patients with bilateral SPT showed bilateral hyperdensities at the level of the inferior olive, which was interpreted as olivary pseudohypertrophy. ${ }^{7}$ Brain MRI of patients with unilateral SPT showed only unilateral, left sided olivary pseudohypertrophy (contralateral to the side of palatal tremor and the cerebellar syndrome). Brain MRI of the patients with EPT was normal.

EYEBLINK CONDITIONING

Conditioned responses were produced by the normal subjects as early as in the first block of paired stimuli. Figure 1A shows the responses to paired conditioned and unconditioned stimuli and to the conditioned stimulus alone for a patient with EPT, whose responses were similar to those of the normal subjects, and fig $1 \mathrm{~B}$ shows a patient with SPT, whose responses were almost absent. In normal subjects, the conditioned responses increased during the first four blocks of paired stimuli, but reached a plateau thereafter (fig 2). Figure 3 shows the patients' results with respect to the $98 \%$ confidence intervals for the normal subjects. In patients with SPT $(5,8$, and 9) who had bilateral palatal tremor and MRI evidence of abnormalities of both inferior olives, conditioning was abnormal bilaterally. In patients with unilateral SPT, conditioning was abnormal unilaterally, on the side of the palatal tremor, in one (6), and normal bilaterally in the other two ( 7 and 10), who had the mildest cerebellar symptomatology (table and Deuschl
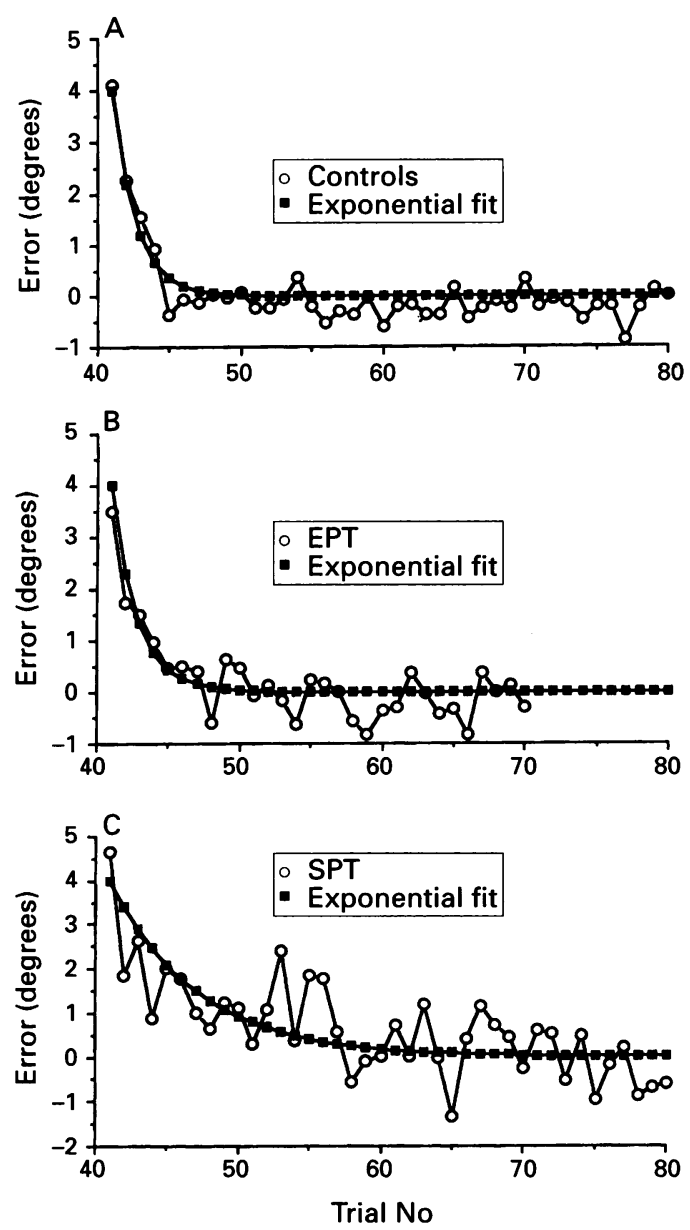

Figure 5 Normalised mean error curves and their exponential fits for both arms of normal subjects $(A)$, patients with EPT $(B)$, and patients with $S P T$ (except patient 8) (C). The fitted curves are similar for normal subjects and patients with EPT, but less steep for the patients with SPT. The variance is also higher in the SPT group. The error values after the change of the gain (trials 41-80) were normalised by subtracting the mean value of the baseline trials (trials 1-40) from each trial and an exponential curve was fitted according to a least mean square paradigm.

et $\left.a l^{7}\right)$. By contrast, some patients with EPT $(1,2$, and 4) had normal conditioning, but patient 3, who had no clinical abnormalities other than palatal tremor and no abnormal signals on the MRI, had abnormal conditioning.

\section{ADAPTATION MOTOR LEARNING}

With the exception of patient 8 , all subjects could perform the adaptation motor learning task without difficulty. After the change of gain, all of them showed some adaptation to the new movement amplitude. The normal subjects and patients with EPT rapidly adapted to the new gain (fig 4A), but the patients with SPT, who had slightly larger movement amplitudes during the baseline condition, were slower to adapt to the new target amplitude (fig 4B). The $\tau$ value, a measure of the number of trials necessary for adaptation motor learning to reach the baseline error, ${ }^{13}$ was 1.66 for the normal subjects (fig 5A) and 1.82 for the patients with EPT (fig 5B), but was clearly larger (8.36) for the patients with SPT (fig 5C). The residual vari- 


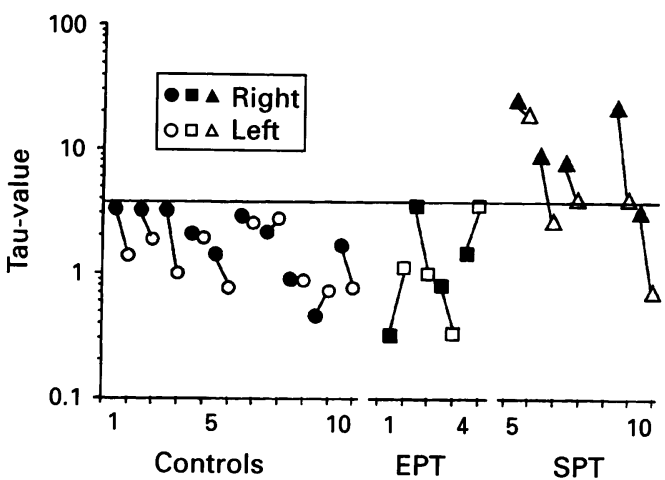

Figure $6 \tau$ Values of the individual error curves for each arm of each subject. The values for the normal subjects define the normal range, the upper limit of which is indicated by the horizontal line. The values for the patients with EPT are within the normal limits, whereas the values for all but one patient with SPT were abnormal. Learning with the unaffected arms of the patients with unilateral SPT (6, 7, and 10) was generally within the normal range. Learning with the affected side was normal only in patient 10 .

ance was 0.34 for the normal subjects, 0.38 for the patients with EPT, and 1.15 for the patients with SPT. The duration of the movements was slightly longer for the patients with SPT than for the patients with EPT and normal subjects, but after the change of gain, there was no significant increase of the movement duration in any of the groups. The $\tau$ values for both the right and left arms of the patients with EPT were within the normal range, whereas those of the patients with SPT were higher for most of the arms (fig 6). Both patients with bilateral SPT (patients 5 and 9) had abnormal $\tau$ values bilaterally. Patient 8 had oscillopsia and could not be tested. Of the patients with unilateral SPT, patients 6 and 7 had abnormal $\tau$ values on the affected right side, and patient 10 had normal values.

\section{Discussion}

The present findings are consistent with the idea that motor learning in humans depends on an intact olivocerebellar system. Although the two different learning paradigms that we used may involve different parts of the olivocerebellar circuitries, they nevertheless often disclosed abnormalities in patients with SPT and olivary pseudohypertrophy.

Classical conditioning was abnormal unilaterally or bilaterally in all but two of the patients with SPT and was normal in all but one of the patients with EPT. As the orbicularis oculi reflexes were present, we assume that their reflex pathways were largely intact. ${ }^{7}$ Therefore, the functional circuitries mediating conditioned learning are probably affected. Various brain stem and cerebellar structures play a part in conditioning learning in animals. Many studies in rabbits (see reviews ${ }^{111}$ ) have focused on the circuits in a classical conditioning paradigm, analysing nictitating membrane responses to unconditioned stimuli (air puffs delivered to the cornea or electrical stimuli to the supraorbital nerve) and to conditioned stimuli (acoustic tones). The results of these studies showed that the unconditioned stimulus is mediated through the inferior olive to the contralateral cerebellum via the climbing fibres and is integrated at the cerebellar Purkinje cells and the interpositus nucleus and that the conditioned stimulus is mediated via the pontine nuclei and their mossy fibre system. This "learned" association is believed to influence the supranuclear reflex centres for the corneal reflex via the red nucleus. ${ }^{10}$

According to the Albus-Marr model of learning, ${ }^{1516}$ the conditioned response in normal subjects could be produced by the interaction of the unconditioned stimulus (electrical nerve shock) with the conditioned stimulus (tone). The first stimulus might be mediated through the contralateral inferior olive and the second through the pontocerebellar pathways to interact at the level of the cerebellar Purkinje cells. ${ }^{17}$ In rabbits studied with the nictitating membrane paradigm, ${ }^{18}$ lesions of the inferior olive extinguished conditioned learning. As all of our patients had morphologically intact cerebellar hemispheres, the defective conditioning is likely be due to lesions of the pathways to or from the cerebellum. Among those pathways, the inferior olive is one of the likely candidates. Although we cannot definitely exclude other brain stem structures as having a role in the defective conditioning, the morphological abnormality of the inferior olive is the consistent abnormality in all of our patients. Experiments in cats ${ }^{19}$ suggest that lesions of the inferior olive indeed produce functional deficits resembling cerebellar abnormalities, and clinical findings in our patients with SPT were similar. ${ }^{7}$

Because at least two of the patients with SPT (7 and 10) had normal conditioning, the most conservative conclusion might be that conditioning learning can take place even when the presumed pseudohypertrophy of the inferior olive is present. However, these were the least affected patients, with possibly incomplete lesions of the inferior olive, which did not involve the pathways for conditioning. This possibility is not unlikely, as the inferior olive is known to be somatotopically organised. ${ }^{2021}$ One of the patients with EPT (patient 3) had abnormal conditioning for uncertain reasons. Our most important finding, however, is that most of the patients with SPT had unilateral or bilateral abnormal conditioning learning, which supports the suggestion that the olivocerebellar system is involved in conditioning learning. This finding confirms earlier findings in animals ${ }^{1018}$ and in patients with cerebellar disease, ${ }^{12}$ and adds the notion that functional deficits presumably confined to the inferior olive can impair conditioning.

The second paradigm analysed adaptation learning in a different situation involving the somatosensory system of the arm and the visual system used as the feedback system. This paradigm breaks up the naturally occurring and usually very rapid adaptation to a changing force, weight, or distance into discrete events, ${ }^{22}{ }^{23}$ which can be quantified. Thereby, the speed of adaptation to these 
changes of gain can be studied. ${ }^{24} 25$ We have already shown ${ }^{13}$ that adaptation usually occurs within seven trials in normal subjects and is abnormal in patients with cerebellar disease. In the present study, this paradigm showed learning abnormalities in all but one of the patients with SPT but normal learning in the patients with EPT. The abnormality was confined to the side contralateral to the hypertrophied inferior olive. The one patient with olivary hypertrophy but normal learning with the affected arm (patient 10) also had normal eye blink conditioning (fig 3), possibly indicating only mild disturbances of the olivocerebellar system. These findings confirm and extend earlier findings in four patients with palatal tremor tested with a throwing paradigm during normal and prism distorted vision, ${ }^{92526}$ of whom only two had abnormal learning. According to Fitts' law, ${ }^{27}$ there is a trade off between the speed and the accuracy of a movement. In the present case, however, this cannot account for our result, as the duration of the movement did not significantly change after the change of the gain. Clinically, all of the patients with SPT had motor disturbances of the investigated arm, indicating a functional disturbance of either the cerebellum or its afferent or efferent pathways. ${ }^{7}$ There are reasons to believe that in at least three of our patients $(5,7$, and 10$)$ the lesion was confined to the inferior olive. ${ }^{7}$ Hence, our finding of abnormal learning provides evidence that the inferior olive is involved in proprioceptive calibration as a form of adaptation motor learning.

The interpretation of abnormal learning in the case of palatal tremor is very similar to the one for classical conditioning. According to the Albus-Marr model of cerebellar learning, ${ }^{1516}$ we assume that the visually mediated feedback information, together with the contextual information about the motor task, is mediated through the pontocerebellar system, and the olivocerebellar system provides the relevant proprioceptive information about the position and movement of the involved arm. Both are thought to be integrated at the cerebellar level and provide an optimised output signal transmitted through the efferent cerebellar pathways. By reversible blockade of different areas with muscimol, the cerebellar cortical area responsible for this learning to occur in monkeys was recently determined to be located in the extreme lateral cerebellar hemisphere. ${ }^{28}$ The absence or abnormality of input through the olivocerebellar system is thought to be responsible for defective learning in patients with SPT, but the test of adaptation motor learning does not provide any evidence of abnormal learning in patients with EPT.

In the present study, the finding of abnormal learning in patients with SPT but not EPT, with two different learning paradigms, lends support to our contention that SPT and EPT are distinct entities, with involvement of the olivocerebellar system only in SPT. Further, because of the focality of lesions in some of our patients, we suggest that the inferior olive is most likely involved in the two forms of motor learning that we tested. Hence, the data can be interpreted as further confirmation of the Albus-Marr model of motor learning.

We thank Dr F Aiple for help with the statistical analysis of the data, Mrs B Guschlbauer for technical assistance with the data analysis, Mrs W Vasold for editorial assistance, and Ms B Hessie for skilful editing. Some of the patients were referred by Dr D S Zee, from the Department of Neurology, Johns Hopkins Hospital, Baltimore, MD. GD was supported by the Deutsche Forschungsgemeinschaft.

1 Lapresle J. Rhythmic palatal myoclonus and the dentatoolivary pathway. $\mathcal{F}$ Neurol $1979 ; 220: 223-30$.

2 Lapresle J. Palatal myoclonus. Adv Neurol 1986;43:265-73.

3 Dubinsky RM, Hallett M. Palatal myoclonus and facial involvement in other types of myoclonus. In: Jankovic J, Tolosa E, eds. Facial dyskinesias. New York: Raven Press, 1988:263-78.

4 Koeppen AH, Barron KD, Dentinger MP. Olivary hypertrophy in man. In: Courville J, De Montigny C, Lamarre $\mathrm{Y}$, eds. The inferior olivary nucleus. Anatomy and physiol ogy. New York: Raven Press, 1980:309-14.

5 Goto N, Kaneko M. Olivary enlargement; chronological and morphometric analyses. Acta Neuropathol 1981;54 275-82.

6 Deuschl G, Mischke G, Schenck E, Schulte-Mönting J, Lücking $\mathrm{CH}$. Symptomatic and essential rhythmic palatal myoclonus. Brain 1990;113:1645-72.

7 Deuschl G, Toro C, Valls-Solé J, Zeffiro T, Zee DS, Hallett M. Symptomatic and essential palatal tremor. 1 . Hallett M. Symptomatic and essential palatal tremor. 1 .
Clinical, physiological and MRI analysis. Brain 1994; Clinical, physid

8 Lalonde R, Botez MI. The cerebellum and learning processes in animals. Brain Res Rev 1990;15:325-32.

9 Thach WT, Goodkin HP, Keating JG. The cerebellum and the adaptive coordination of movement. Annu Rev Neurosci 1992;15:403-42.

10 Thompson RF. Neural mechanisms of classical conditioning in mammals. Philos Trans $R$ Soc Lond (Biol) 1990;64 $161-70$.

11 Yeo CH, Hardiman MJ. Cerebellar cortex and eyeblink conditioning: a reexamination. Exp Brain Res 1992;88: 623-38.

12 Topka H, Valls-Solé J, Hallett M. Deficit in classical conditioning in patients with cerebellar degeneration. Brain 1993;116:961-9.

13 Deuschl G, Toro C, Zeffiro T, Massaquoi S, Hallett $M$. Adaptation motor learning of arm movements in patients with cerebellar disease. I Neurol Neurosurg Psychiatry 1996;60:515-9.

14 Sanes JN, Dimitrov B, Hallett M. Motor learning in patients with cerebellar dysfunction. Brain 1990;113 103-20.

5 Albus JS. A theory of cerebellar function. Math Biosci 1971;10:25-61.

16 Marr D. A theory of cerebellar cortex. F Physiol (Lond) 1969;202:437-70.

17 Ito $M$. The cerebellum and neural control. New York: Raven Press, 1984.

18 Yeo CH, Hardiman MJ, Glickstein M. Classical conditioning of the nictitating membrane response of the rabbit. 63:81-92.

19 Murphy GM, O'Leary JL. Neurological deficit in cats with lesions of the olivocerebellar system. Arch Neurol 1971; 24:145-57.

20 Gellman R, Houk JC, Gibson AR. Somatosensory properties of the inferior olive of the cat. $\mathcal{F}$ Comp Neurol 1983; 215:228-43

21 Thach WT, Perry JG, Schieber MH. Cerebellar output: body maps and muscle spindles. Exp Brain Res 1982, 6(suppl):440-54.

22 Hallett M, Shahani BT, Young RR. EMG analysis of stereotyped voluntary movements in man. $\mathcal{f}$ Neurol Neurosurg Psychiatry 1975;38:1 154-62.

23 Gordon J, Ghez C. Trajectory control in targeted force Gordon J, Ghez C. Trajectory control in
impulses. Exp Brain Res 1987;67:241-52.

24 Weiner MJ, Hallett M, Funkenstein HH. Adaptation to lateiner MJ, Hallett $M$, Funkenstein $\mathrm{HH}$. Adaptation to lat-
eral displacement of vision in patients with lesions of the eral displacement of vision in patients with lesions
central nervous system. Neurology 1983;33:766-72.

25 Kane SA, Thach WT. Palatal myoclonus and function of the inferior olive: are they related? In: Strata $\mathrm{P}$, ed. The olivocerebellar system in motor control. Berlin: SpringerVerlag, 1989:427-60.

26 Thach WT, Keating JG, Goodkin HP. Inferior olive disease in man impairs learning novel synergies. Soc Neurosci Abstr 1991;17:1380.

27 Fitts PM. The information capacity of the human motor system in controlling the amplitude of movement. $\mathcal{F}$ Exp Psychol 1954;67:381-91.

28 Keating JG, Thach WT. The cerebellar cortical area required for adaptation of monkey's "jump" task is lateral, localized and small. Soc Neurosci Abstr 1991;17: 1381 . 